\title{
Lumbar interbody fusion after treatment with recombinant human bone morphogenetic protein-2 added to 70:30 poly(L-lactide-co-D,L-lactide) bioresorbable implants
}

\author{
Todd H. Lanman, M.D., and Thomas J. Hopkins, PH.D., M.D. \\ DBA California Spine Group, and Century City Hospital, Los Angeles, California
}

\begin{abstract}
Object. To evaluate the effectiveness of recombinant human bone morphogenetic protein-2 (rhBMP-2) combined with a bioresorbable implant, the authors conducted a prospective study of 43 patients with degenerative lumbar disc disease who underwent transforaminal lumbar interbody fusion.

Methods. The authors used Infuse bone graft, which consisted of rhBMP-2 applied to an absorbable collagen sponge and contained within a HYDROSORB Telamon bioresorbable implant to perform the fusion. Multilevel fusions were performed in $30 \%$ of the 43 patients, for a total of 57 levels. At 6 months postoperatively, x-ray films and computerized tomography (CT) scans demonstrated solid fusion in $98 \%$ of 41 patients. Improvement from the baseline Oswestry Disability Rating was demonstrated at 6 months postoperatively in $68 \%$ of the patients, based on the Oswestry Disability Questionnaire. At 12 months all 11 patients in whom CT scans were obtained showed complete bridging of bone; there were no device-related complications.

Conclusions. Results in this series provide evidence of the feasibility of using HYDROSORB Telamon bioresorbable spacers in combination with Infuse bone graft for lumbar spine fusion.
\end{abstract}

\section{KEY WORDS - lumbar spine fusion - bone morphogenetic protein • bioresorbable implant $\bullet$ interbody cage}

Interbody fusions have historically involved bone grafts to produce intervertebral arthrodesis in the treatment of degenerative disc disease. Cloward ${ }^{9,10}$ pioneered this effort and was able to achieve notable success in his patients by performing PLIFs starting in the 1940s, and anterior cervical interbody fusions in the 1950s. The challenging surgical technique and the need for meticulous graft preparation, however, discouraged widespread adoption of these methodologies.

Metallic spinal interbody devices were initially introduced in the setting of veterinary medicine with the Bagby stainless steel fenestrated device being used to treat equine spinal instability in the 1970 s. ${ }^{12}$ Subsequently, revived interest in human clinical applications sparked pursuit of designs for rectangular, cylindrical, ring, and threaded interbody geometries. ${ }^{1,13,17,23}$ Such devices were commonly packed with morselized autologous bone chips. Surgical approaches included posterior, anterior, or transforaminal procedures. . $22,23,26^{2}$

\footnotetext{
Abbreviations used in this paper: $\mathrm{CT}=$ computerized tomography; $\mathrm{PLa}=70: 30$ poly $(\mathrm{L}-$ lactide-co-D, $\mathrm{L}-$ lactide $) ; \mathrm{PLIF}=$ posterior lumbar interbody fusion; rhBMP-2 = recombinant human bone morphogenetic protein-2; TLIF = transforaminal lumbar interbody fusion.
}

Metal interbody devices were typically very strong and rigid, but had the problem of excessive stiffness, which led to stress shielding and implant subsidence. ${ }^{20,21} \mathrm{Ra}-$ diological scatter and distortion were also problems, and were particularly challenging when attempts were made to assess fusion radiographically. Cortical bone interbody devices with more physiological biomechanical and radiological compatibility have been used but donor bone availability and disease transmission concerns were an issue. Autologous bone from iliac crest harvest was also used, but this method introduced additional complications and morbidities.

More recently, synthetic materials have been used that exhibit the promising biomechanical and neuroimaging advantages of nonmetal implants, and eliminate the supply issues associated with allograft tissue, as well as perceived disease transmission issues. ${ }^{25}$ Materials such as carbon composite and polyethylethylketone $\mathrm{e}^{7,18}$ have been used to some degree; with these, however, a permanent foreign body mass remains that can yield potential longterm complications, and there is no possibility for the space occupied by the implant to be remodeled into bone. One group of materials of particular interest are bioresorbable polymers that gradually degrade into biologically innocuous end products (water and carbon dioxide) 
over time, with no long-term residual foreign body presence. ${ }^{25}$ Various bioresorbable materials have been used in the medical industry, with synthetic formulations made from polyglycolide and polylactide being most popular. ${ }^{15,16}$ Studies comparing these two polymers have shown that the polyglycolide implants tend to biodegrade faster and have higher complication rates than their polylactide counterparts. ${ }^{6}$

HYDROSORB polylactide devices (distributed by Medtronic Sofamor Danek, Memphis, TN), which are intended for support of weak bone tissue have been used by some investigators as potential interbody devices. The HYDROSORB copolymer of polylactide, PLa, has been used in various laboratory, preclinical, and clinical studies in a variety of clinically relevant situations. Results of laboratory tests have indicated that the PLa degrades over a period of 18 to 36 months. ${ }^{11}$

Animal studies have been conducted that involve resorbable devices used for interbody fusion. In one study, researchers looked at devices constructed of a PLa polymer that were implanted with and without rhBMP-2 in 25 sheep and evaluated over a period of 24 months. ${ }^{24}$ Comparable steadily increasing degrees of fusion were observed mechanically and histologically over the time period, with the resorbable spacer filled with either rhBMP-2 or autograft bone. Additionally, when the implant was resorbed at the 24-month period, the space was replaced with remodeled bone, with normal bone mineralization adjacent to the device and no osteolysis was found. These findings are comparable with another study, in which lumbar interbody devices composed of poly-L-lactide were investigated in 36 goats. ${ }^{27}$ Fusion appeared to occur at approximately 2 years, and it was faster and more complete than when identically shaped titanium cages were used. Tissue reaction in both studies was described as mild to moderate.

Clinically, bioresorbable interbody devices have been used with encouraging results. In one study ${ }^{19} 60$ patients who underwent TLIF procedures experienced no adverse events or complications at up to 9 months. In another report, ${ }^{2}$ PLa implants were used as PLIF devices in 15 patients, with 1-year results that were comparable to those of bone spacers. Yet another group of researchers ${ }^{3}$ reported on an additional 12 patients who underwent PLIF with at least 1 year of follow up in whom successful clinical and neuroimaging results were demonstrated 12 to 18 months postsurgery.

Recently, the use of rhBMP-2 has been shown to initiate osteoinduction and to achieve spinal arthrodesis in animals and in humans. ${ }^{4,5,24}$ Human clinical trials of lumbar and cervical fusion have demonstrated consistent and clear osteoinduction when an absorbable collagen sponge is impregnated with rhBMP- $2 .{ }^{8}$

We present 3- to 12-month follow-up information in a series of 43 patients in whom a bioresorbable device combined with an rhBMP-2 filler was placed as a lumbar interbody implant for TLIF over one or two levels.

\section{CLINICAL MATERIAL AND METHODS}

We conducted a prospective evaluation of medical charts, x-ray films, and CT scans in all patients who had undergone lumbar fusion in which a bioresorbable orthopedic implant, HYDROSORB Telamon (Medtronic Sofamor Danek) was used as an interbody spacer to contain Infuse bone graft (Medtronic Sofamor Danek). HYDROSORB Telamon is a noncrystalline polylactide copolymer with a 70:30 ratio of poly(L-lactide) to poly(D,L-lactide).

\section{Patient Population}

A total of 43 patients were chosen for this surgical procedure between September 19, 2002, and July 3, 2003. Patients ranged in age from 17 to 68 years (mean 48.6 years). There were 19 female (44\%) and 24 male (56\%) patients. Thirty-four patients $(79 \%)$ were scheduled for lumbar fusion because of discogenic pain. Of the remaining patients, five (12\%) had Grade I spondylosis and four $(9 \%)$ had a nonunion from previous surgery. The majority (70\%) underwent one-level fusion, and in 30\% two levels were fused, for a total of 56 levels. Patient data are summarized in Table 1.

Each patient underwent the standard TLIF procedure except for one in whom an anterior procedure was performed. Approximately half of the surgeries were completed percutaneously and half were open procedures. The rhBMP-2 solution was reconstituted and applied to a piece of collagen sponge according to the directions for use with Infuse. The Infuse was then contained within the HYDROSORB Telamon bioresorbable orthopedic implants,

TABLE 1

Summary of characteristics in 43 patients who underwent lumbar interbody fusion*

\begin{tabular}{ll}
\hline \multicolumn{1}{c}{ Characteristic } & Value \\
\hline no. treated & 43 \\
age (yrs) & \\
mean \pm SD & $48.6 \pm 10.5$ \\
range & $17-68$ \\
sex & \\
female & $19(44 \%)$ \\
male & $24(56 \%)$ \\
diagnosis & $34(79 \%)$ \\
discogenic pain & $5(12 \%)$ \\
Grade I spondylosis & $4(9 \%)$ \\
nonunion & $30(70 \%)$ \\
no. w/ one level fused & 12 \\
L5-S1 & 11 \\
L4-L5 & 4 \\
L3-L4 & 2 \\
L2-L3 & 1 \\
L1-L2 & $13(30 \%)$ \\
no. w/ two levels fused & 12 \\
L4-5, L5-S1 & 1 \\
L3-4, L4-5 & \\
length of stay (days) & $2.9 \pm 1.22$ \\
mean \pm SD & $1-6$ \\
range & \\
length of FU (mos) & $9.8 \pm 2.71$ \\
mean \pm SD & $5-15$ \\
range & $19(45 \%)$ \\
no. w/ fusion & $40(98 \%)$ \\
3-mo FU, 42 patients & $11(100 \%)$ \\
6-mo FU, 41 patients & \\
12-mo FU, 11 patients & \\
\hline
\end{tabular}

$* \mathrm{FU}=$ follow up; $\mathrm{SD}=$ standard deviation. 
which were tapped into place for each level to be fused. Instrumentation consisting of the CD Horizon spinal system (57\%), the TSRH-3D system (36\%), or the Blackstone spinal fixation system was used in conjunction with the interbody spacer and graft.

As part of a standardized evaluation process, we obtained preoperative plain $\mathrm{x}$-ray films and CT scans in all patients to document degenerative disc disease, and all patients also were asked to complete a baseline Oswestry Disability Questionnaire. ${ }^{14}$ At follow-up visits plain x-ray films, CT scans, and Oswestry questionnaires were obtained to determine the fusion rates and Oswestry Disability Rating after surgery. Fusion was defined as bridging bone in the interbody space from the vertebra through the graft to the adjacent vertebra that was observed on CT scans. The postoperative regimen included the following instructions to be followed for 6 weeks until the first postoperative visit: 1) no lifting of loads heavier than $20 \mathrm{lb}$;2) walk daily; 3 ) limit sitting to 2 hours three times per day; 4) may drive short distances after 1 week; and 5) may shower and get the wound wet.

\section{RESULTS}

One-level fusion was performed in $30(70 \%)$ and twolevel fusion in 13 patients (30\%). The mean length of stay after surgery was 3 days (range 1-6 days). One of the original 43 patients was lost to follow up; therefore the results are reported on 42 patients. At the 3-month follow-up evaluation, successful interbody fusion was observed on CT scans in 19 patients (45\%), including three in whom two levels were fused. At 6 months 40 (98\%) of 41 patients exhibited interbody fusion. All 13 patients (100\%) in whom two levels were fused displayed interbody fusion at all levels at the 6-month time point. All 11 patients in whom CT scans were obtained at the 12-month follow-up review continued to show solid fusion.

\section{Illustrative Case}

The patient in Case 2 was a 42-year-old man with discogenic low-back pain. Figure 1 presents his preoperative magnetic resonance image. Figure 2 displays the sag-

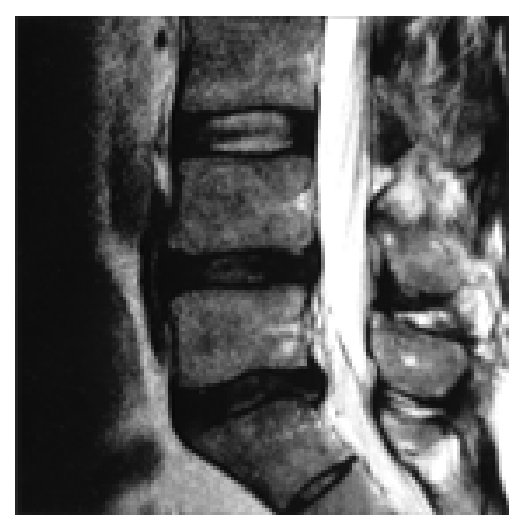

Fig. 1. Case 2. Preoperative sagittal magnetic resonance image demonstrating the affected area in a patient with discogenic lowback pain.

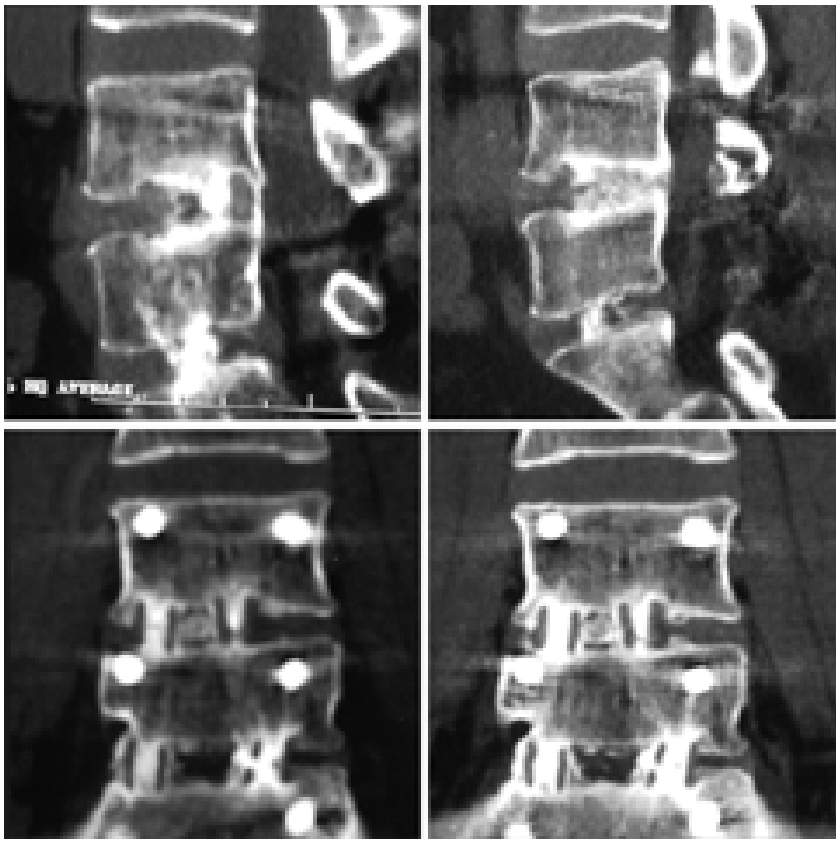

Fig. 2. Case 2. Upper: Sagittal CT scans. Six-month followup scan is on the left and 12-month scan is on the right. Lower: Coronal CT scans. Six-month follow-up scan is on the left and 12month scan is on the right.

ittal and coronal views from his 3- and 6-month follow-up CT scans.

There were no device-related complications. One patient suffered a dural tear on the nerve root sleeve, which was repaired primarily. This patient exhibited numbness of the right leg, which resolved in 3 weeks. Solid bone bridging was present on CT scans obtained at 6 months. A summary of the mean of all Oswestry scores is shown in Table 2 . The mean disability score showed improvement over baseline (decrease in \% disability) at all postoperative visits. Not all patients completed the Oswestry Disability Questionnaire at every follow-up visit: 23 patients completed the questionnaire at the preoperative and at least one postoperative visit. Comparisons of individual patients' scores show that in close to $70 \%$ scores improved at the 3-and 6-month postoperative time points (Table 3). The mean improvement in disability scores from the preoperative values at 3 and 6 months was 6 and $9 \%$, respectively. The nine patients who completed the questionnaire 12 months postoperatively maintained a $9 \%$ decrease in disability from the baseline score. One patient had a $60 \%$ decrease in disability at 12 months.

TABLE 2

Patients' mean scores on the Oswestry Disability Questionnaire

\begin{tabular}{ccccc}
\hline \hline Factor & Preop & 3 Mos & 6 Mos & 12 Mos \\
\hline $\begin{array}{l}\text { no. of patients } \\
\text { mean Disability Index } \\
\text { score for all entries } \\
(\% \pm \text { SD) }\end{array}$ & 25 & 22 & 23 & 9 \\
& & & & \\
\hline
\end{tabular}


TABLE 3

Change in individual Oswestry Disability Index scores

\begin{tabular}{|c|c|c|c|c|c|}
\hline \multirow{2}{*}{$\begin{array}{l}\text { Time } \\
\text { Postop }\end{array}$} & \multirow{2}{*}{$\begin{array}{l}\text { No. of } \\
\text { Patients }\end{array}$} & \multirow{2}{*}{$\begin{array}{c}\text { Mean Change } \\
\text { From Preop } \\
\text { Score }(\% \pm \mathrm{SD}) *\end{array}$} & \multicolumn{3}{|c|}{ No. of Patients (\%) } \\
\hline & & & Improved & Worse & Same \\
\hline $3 \mathrm{mos}$ & 19 & $\begin{array}{c}6 \pm 18.2 \\
\text { range }-20 \text { to }+44\end{array}$ & $13(68)$ & $6(32)$ & 0 \\
\hline $6 \mathrm{mos}$ & 19 & $\begin{array}{c}9 \pm 18.2 \\
\text { range }-18 \text { to }+58\end{array}$ & $13(68)$ & $6(32)$ & 0 \\
\hline $12 \mathrm{mos}$ & 9 & $\begin{array}{c}9 \pm 18.8 \\
\text { range }-8 \text { to }+60\end{array}$ & $6(67)$ & $2(22)$ & $1(11)$ \\
\hline
\end{tabular}

* The pluses indicate improvement, that is, lower percent disability.

\section{DISCUSSION}

Bioresorbable materials have been used for various applications in spinal surgery, including iliac reconstruction, cervical plating and screws, and lumbar interbody spacers. Researchers have used PLa in a variety of animal models and clinical spinal scenarios, with promising results. It has also been noted that rhBMP-2 has been used successfully to augment standard lumbar interbody fusion procedures. ${ }^{8}$

This prospective study is among the first reported patient series in which rhBMP-2 has been used in conjunction with a bioresorbable interbody spacer for a PLIF procedure. In our practice, we believe that fusion occurs earlier and is easier to assess when Infuse is used with HYDROSORB Telamon, compared with Infuse used in conjunction with an allograft interbody spacer or titanium cage. This report involves a relatively small number of patients who have had a short follow-up time. Nevertheless, it is encouraging to note that bridging bone was clearly visible on plain X-ray films and CT scans at the 6-month follow-up examination in $98 \%$ of patients. It is too early to draw conclusions about this combination of materials for PLIF, but the initial results indicate that this may copolymer provide an alternative treatment for lumbar fusion. These patients will continue to be followed up to confirm long-term success with the use of a bioresorbable interbody spacer in conjunction with rhBMP-2 for this condition.

\section{Disclosure}

Dr. Todd Lanman is a paid consultant for Medtronic Sofamor Danek, Inc.

\section{References}

1. Agazzi S, Reverdin A, May D: Posterior lumbar interbody fusion with cages: an independent review of 71 cases. J Neurosurg (Spine 2) 91:186-192, 1999

2. Alexander JT, Branch CL Jr, Subach BR, et al: Applications of a resorbable interbody spacer via a posterior lumbar interbody fusion technique. Orthopedics 25 (Suppl 10):S1185-S1189, 2002

3. Austin RC, Branch CL Jr, Alexander JT: Novel bioabsorbable interbody fusion spacer-assisted fusion for correction of spinal deformity. Neurosurg Focus 14 (1):Article 11, 2003

4. Baskin DS, Ryan P, Sonntag V, et al: A prospective, randomized, controlled cervical fusion study using recombinant human bone morphogenetic protein-2 with the Cornerstone-SR allograft ring and the Atlantis anterior cervical plate. Spine 28: 1219-1225, 2003

5. Boden SD, Zdeblick TA, Sandhu HS, et al: The use of rhBMP-
2 in interbody fusion cages. Definitive evidence of osteoinduction in humans: a preliminary report. Spine 25:376-381, 2000

6. Bostman O, Pihlajamaki H: Clinical biocompatibility of biodegradable orthopaedic implants for internal fixation: a review. Biomaterials 21:2615-2621, 2000

7. Brantigan JW, Steffee AD, Geiger JM: A carbon fiber implant to aid interbody lumbar fusion. Mechanical testing. Spine 16 (Suppl 6):S277-S282, 1991

8. Burkus JK, Dorchak JD, Sanders DL: Radiographic assessment of interbody fusion using recombinant human bone morphogenetic protein type 2. Spine 28:372-377, 2003

9. Cloward RB: The treatment of ruptured lumbar intervertebral disc by vertebral body fusion. III. Method of use of banked bone. Ann Surg 136:987-992, 1952

10. Cloward RB: Vertebral body fusion for ruptured cervical discs. Am J Surg 98:722-727, 1959

11. Cohen SR, Holmes RE, Amis P, et al: Tacks: a new technique for craniofacial fixation. J Craniofac Surg 12:596-602, 2001

12. DeBowes RM, Grant BD, Bagby GW, et al: Cervical vertebral interbody fusion in the horse: a comparative study of bovine xenografts and autografts supported by stainless steel baskets. Am J Vet Res 45:191-199, 1984

13. Dewald CJ, Millikan KW, Hammerberg KW, et al: An open, minimally invasive approach to the lumbar spine. Am Surg 65: 61-68, 1999

14. Fairbank JC, Pynsent PB: The Oswestry Disability Index. Spine 25:2940-2952, 2000

15. Hofmann GO, Wagner FD: New implant designs for bioresorbable devices in orthopaedic surgery. Clin Mater 14: 207-215, 1993

16. Hollinger JO: Preliminary report on the osteogenic potential of a biodegradable copolymer of polyactide (PLA) and polyglycolide (PGA). J Biomed Mater Res 17:71-82, 1983

17. Janssen ME, Nguyen C, Beckham R, et al: Biological cages. Eur Spine J 9 (Suppl 1):S102-S109, 2000

18. Krammer M, Dietl R, Lumenta CB, et al: Resistance of the lumbar spine against axial compression forces after implantation of three different posterior lumbar interbody cages. Acta Neurochir 143:1217-1222, 2001

19. Lowe TG, Coe JD: Bioresorbable polymer implants in the unilateral transforaminal lumbar interbody fusion procedure. Orthopedics 25 (Suppl 10):S1179-S1183, 2002

20. Matge G: Cervical cage fusion with 5 different implants: 250 cases. Acta Neurochir 144:539-550, 2002

21. Murakami H, Boden SD, Hutton WC: Anterior lumbar interbody fusion using a barbell-shaped cage: a biomechanical comparison. J Spinal Disord 14:385-392, 2001

22. Rajaraman V, Vingan R, Roth $P$, et al: Visceral and vascular complications resulting from anterior lumbar interbody fusion. J Neurosurg (Spine 1) 91:60-64, 1999

23. Ray CD: Threaded titanium cages for lumbar interbody fusions. Spine 22:667-680, 1997

24. Toth JM, Estes BT, Wang M, et al: Evaluation of 70/30 poly (Llactide-co-D,L-lactide) for use as a resorbable interbody fusion cage. J Neurosurg (Spine 4) 97:423-432, 2002

25. Vaccaro AR, Madigan L: Spinal applications of bioabsorbable implants. J Neurosurg (Spine 4) 97:407-412, 2002

26. Whitecloud TS III, Roesch WW, Ricciardi JE: Transforaminal interbody fusion versus anterior-posterior interbody fusion of the lumbar spine: a financial analysis. J Spinal Disord 14: 100-103, 2001

27. Wuisman PI, van Dijk M, Smit TH: Resorbable cages for spinal fusion: an experimental goat model. J Neurosurg (Spine 4) 97: 433-439, 2002

Manuscript received January 15, 2004.

Accepted in final form February 10, 2004.

Address reprint requests to: Todd H. Lanman, M.D., Southern California Association of Neurological Surgeons, 8631 West Third Street, Suite 945E, Los Angeles, California 90048. email: toddlanman@aol.com. 